Vietnam Journal of Mechanics, VAST, Vol.40, No.3 (2018), pp. 199-215

DOI: https://doi.org/10.15625/0866-7136/10776

\title{
FREE VIBRATION ANALYSIS OF FUNCTIONALLY GRADED SHELL PANELS WITH VARIOUS GEOMETRIC SHAPES IN THERMAL ENVIRONMENT
}

\author{
Duong Thanh Huan ${ }^{1, *}$, Tran Huu Quoc ${ }^{2}$, Tran Minh Tu${ }^{2}$ \\ ${ }^{1}$ Vietnam National University of Agriculture, Hanoi, Vietnam \\ ${ }^{2}$ National University of Civil Engineering, Hanoi, Vietnam \\ *E-mail: dthuan@vnua.edu.vn \\ Received November 27, 2017
}

\begin{abstract}
This paper presents free vibration analysis of functionally graded materials (FGMs) shell panels with various geometric shapes in thermal environments. The shell panels are made from a mixture of metal and ceramic. Material properties are assumed to be temperature-dependent and graded in the thickness direction according to a power law function. A formulation of eight-nodded middle surface shell elements based on Reissner-Mindlin assumptions is developed for modeling FGM shell panels under the effect of temperature, which changes nonlinearly across the thickness. Numerical results obtained by the proposed model are in good agreement with those available in the literature. The effects of geometric properties, material composition, boundary conditions and temperature on the natural frequencies are investigated.

Keywords: functionally graded materials, finite element method (FEM), free vibration, shell panels, various geometric shapes, thermal environment.
\end{abstract}

\section{INTRODUCTION}

Functionally graded materials (FGMs) are classified as novel composite materials. They are microscopically inhomogeneous and typically made of metal and ceramic. By gradually changing the volume fraction of constituent materials, their mechanical and thermal properties vary smoothly and continuously from one surface to the other, thus eliminating interface problems and reducing thermal stress concentration. The ceramic component offers thermal barrier effects and protects the metal from corrosion and oxidation, while the metal component provides toughness and strength. Due to their excellent features, FGMs are now widely used in many engineering applications, especially for high-temperature environments such as nuclear reactors, spacecrafts, civil engineering, electronic or chemical energy sources ...

Panel-type structures are among the most commonly used structural components in various fields of mechanical and structural engineering. Since most of them usually

(C) 2018 Vietnam Academy of Science and Technology 
work in high-temperature environments, the designs of these structures have to carefully consider the thermal effect on structural and material behavior.

Many studies have been conducted in recent years to analyze the thermo-mechanical behaviors of FG shells. Based on the first-order shear deformation plate theory (FSDT), Reddy and Chin [1] analyzed the thermoelastic dynamic response of functionally graded cylinders and plates. Using the element-free $k p$-Ritz method based on FSDT, Zhao et al. [2] investigated the thermoelastic vibration of FGM shell panels. Love's shell theory and Rayleigh-Ritz method were used to study the natural vibration of functionally graded cylindrical shells by Loy et al. [3]. Using the wave propagation method for solving the shell dynamical equations, Shah et al. [4] studied the vibration characteristic of FG cylindrical shells resting on the Winkler-Pasternak foundations. Jabbari et al. [5] presented the direct method to solve Navier equations for the analysis of a one-dimensional steady-state thermal stresses in a thick hollow FGM cylinder with general types of thermal and mechanical boundary conditions. Vel [6] presented an analytical solution for free and forced vibration of simply supported FG cylindrical shells. The transient temperature and related thermal stresses in the FGM cylinder were analyzed numerically for a model of the mullite-molybdenum FGM system by Awaji and Sivakumar [7]. Different shear deformation shell theories are used to study the vibration of FG cylindrical shells by Najafizaded and Isvandzibaei [8]. In their study, the cylindrical shells are supported by rings and made from a mixture of stainless steel and nickel. Tornabene et al. [9] used the FSDT to analyze the moderately thick conical, cylindrical, and annular plates made of functionally graded material. Takezono et al. [10] presented an analytical formulation based on Sanders elastic shell theory and the finite difference method to examine the thermal stress and deformation for axisymmetrical shells made of FGM and subjected to thermal loading due to fluid. Matsunaga [11] analyzed free vibration and stability of FGM shallow shell with positive, zero and negative Gaussian curvature by using a 2-D higherorder deformation theory and taking into account the effects of transverse shear and normal deformations, and rotatory inertia. The axisymmetric thermoelastic problem of an FG transversely isotropic cylindrical shell was studied by Ye et al. [12]. Liew et al. [13] obtained solution for analysis of the thermomechanical behavior of hollow FGM cylinders. Pradyumna and Bandyopadhyay [14] performed free vibration and buckling behavior of singly and doubly curved of FGM shell panels in thermal environments by using higherorder shear deformation theory. Alijani et al. [15] used doubly-modal energy approach to study nonlinear vibration of doubly curved FGM shells subjected to thermal variations and harmonic excitation. Shen and Wang [16] examined the small and large-amplitude vibrations of FGM rectangular plate resting on two-parameters (Pasternak-type) elastic foundation in thermal environments. This work was then extended to the case of nonlinear vibration of shear deformable FGM cylindrical panels resting on elastic foundation in thermal environment [17]. Wattanasakulpong and Chaikittiratana [18] employed the FSDT for determining natural frequencies of stiffened functionally graded doubly curved shallow shells under two types of linear and nonlinear temperature rise throughout the shell thickness. Based on Reddy's third-order shear deformation shell theory, Quan and Duc [19] investigated nonlinear vibration and dynamic response of thick, imperfect FGM double-curved shallow shells resting on elastic foundations in thermal environments. 
Using FSDT, Bich et al. [20] presented an analytical solution and results on the nonlinear dynamic response and vibration of imperfect eccentrically stiffened FGM double-curved shallow shells on elastic foundation. Non-linear axisymmetric response of FG shallow spherical shells subjected to uniform external pressure in thermal environments have been investigated by Bich and Tung [21]. The equilibrium and compatibility equations for shallow spherical shells are derived and specialized for axisymmetric deformation by using the classical shell theory and taking into account both geometrical nonlinearity and initial geometrical imperfection. Bich and Long [22] used the thin shell theory considering geometrical non-linearity and the Lekhnitskys smeared stiffeners technique to solve dynamic problem of eccentrically stiffened laminated composite shallow shell. Based on the classical thin shell theory, Anh et al. [23] studied the nonlinear stability of functionally graded material (FGM) annular spherical segment resting on elastic foundations in thermal environment. Dong and Dung [24] used the first-order shear deformation theory (FSDT) with von Karman type nonlinearity to investigate nonlinear vibration of FGM sandwich doubly curved shallow shells reinforced by FGM stiffeners subjected to mechanical and thermal loading.

From the literature review, it is observed that most of these studies focused on vibration analyses of FGM shell panels with simple geometric shapes such as cylindrical or spherical shells. There is a limited number of published studies on the vibration analysis of FG shell panels with complex geometric shapes in thermal environment. Hence, the objective of the present work is to develop a finite element model based on FSDT for the vibration analysis of FG shell panels with various geometric shapes. The eightnodded middle surface shell element with five degrees of freedom per node is proposed to carry out the analysis. The surfaces of shell panels are described by a function of Cartesian coordinates and distribution of temperature across the shell thickness is found from steady state heat conduction only in the thickness direction. The presented analysis is verified by comparing the numerical results with those in available literature. The effects of various parameters, such as the volume fraction exponent, side-to-thickness ratio, boundary conditions, curvature and temperature on natural frequencies of various shell panels, namely, cylindrical panel (CYL), spherical panel (SPH), hyperbolic paraboloid panel (HPR), hyper panel (HYP), conoid panel (CON) and parabolic panel (PAR) are investigated and discussed in details.

\section{MATERIAL PROPERTIES}

A ceramic-metal functionally graded shell panel as shown in Fig. 1 is considered. The top surface $(z=h / 2)$ is ceramic rich, and the bottom surface $(z=-h / 2)$ is metal rich. It is assumed that the material properties (such as Young's modulus E, Poisson's ratio $\nu$, mass density $\rho$, coefficient of thermal expansion $\alpha$, thermal conductivity $\kappa$ ) vary along the thickness direction according to the following power-law expression

$$
P(z, T)=\left(P_{c}-P_{m}\right)\left(\frac{z}{h}+\frac{1}{2}\right)^{p}+P_{m}
$$

where $p$ is the volume fraction exponent, $P_{m}$ and $P_{c}$ represent the properties of metal and ceramic, respectively. 


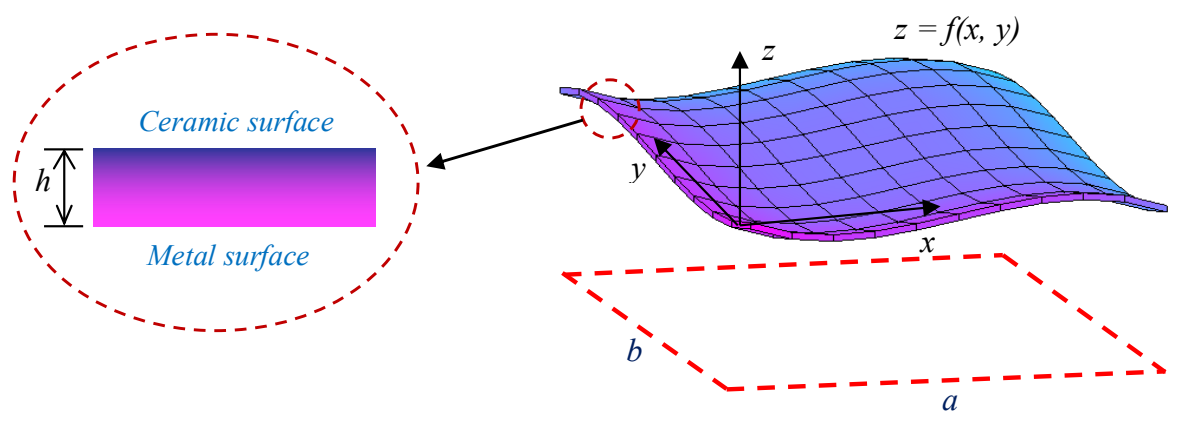

Fig. 1. Panel geometry and coordinate system

The material properties of constituents are assumed to be temperature dependent, and can be expressed as [25]

$$
P(T)=P_{0}\left(P_{-1} T^{-1}+1+P_{1} T+P_{2} T^{2}+P_{3} T^{3}\right),
$$

where $P_{0}, P_{-1}, P_{1}, P_{2}$ and $P_{3}$ are the coefficients of temperature $T$, and are unique for each constituent. The mass density $\rho$ and thermal conductivity $\kappa$ depend weakly on temperature change and are assumed to be function of $z$ only. Thus, material properties can be rewritten as

$$
\begin{aligned}
& E(z, T)=E_{m}(T)+\left[E_{c}(T)-E_{m}(T)\right]\left(\frac{z}{h}+\frac{1}{2}\right)^{p}, \\
& v(z, T)=v_{m}(T)+\left[v_{c}(T)-v_{m}(T)\right]\left(\frac{z}{h}+\frac{1}{2}\right)^{p}, \\
& \alpha(z, T)=\alpha_{m}(T)+\left[\alpha_{c}(T)-\alpha_{m}(T)\right]\left(\frac{z}{h}+\frac{1}{2}\right)^{p}, \\
& \rho(z)=\rho_{m}+\left(\rho_{c}-\rho_{m}\right)\left(\frac{z}{h}+\frac{1}{2}\right)^{p}, \\
& \kappa(z)=\kappa_{m}+\left(\kappa_{c}-\kappa_{m}\right)\left(\frac{z}{h}+\frac{1}{2}\right)^{p} .
\end{aligned}
$$

It is also assumed that the temperature variation occurs only in the thickness direction and the temperature field is constant in the $x-y$ plane. Therefore, the temperature distribution along the thickness direction can be obtained by solving the following steady state one-dimensional heat transfer equation.

$$
-\frac{d}{d z}\left[\kappa(z) \frac{d T}{d z}\right]=0
$$

By imposing the boundary condition: $T=T_{c}$ at $z=h / 2$ and $T=T_{m}$ at $z=-h / 2$, the solution of Eq. (4) can be obtained by means of polynomial series as [26]

$$
T(z)=T_{m}+\left(T_{c}-T_{m}\right) \eta(z),
$$


with

$$
\begin{aligned}
& \eta(z)=\frac{1}{C}\left[\begin{array}{c}
X-\frac{\kappa_{c m}}{(p+1) \kappa_{m}} X^{p+1}+\frac{\kappa_{c m}^{2}}{(2 p+1) \kappa_{m}^{2}} X^{2 p+1} \\
-\frac{\kappa_{c m}^{3}}{(3 p+1) \kappa_{m}^{3}} X^{3 p+1}+\frac{\kappa_{c m}^{4}}{(4 p+1) \kappa_{m}^{4}} X^{4 p+1}-\frac{\kappa_{c m}^{5}}{(5 p+1) \kappa_{m}^{5}} X^{5 p+1}
\end{array}\right], \\
& X=\left(\frac{z}{h}+\frac{1}{2}\right) ; \quad \kappa_{c m}=\kappa_{c}-\kappa_{m}, \\
& C=1-\frac{\kappa_{c m}}{(p+1) \kappa_{m}}+\frac{\kappa_{c m}^{2}}{(2 p+1) \kappa_{m}^{2}}-\frac{\kappa_{c m}^{3}}{(3 p+1) \kappa_{m}^{3}}+\frac{\kappa_{c m}^{4}}{(4 p+1) \kappa_{m}^{4}}-\frac{\kappa_{c m}^{5}}{(5 p+1) \kappa_{m}^{5}} .
\end{aligned}
$$

It can be seen that the temperature distribution in FGMs is a nonlinear function of $z$, and the temperature field is uniform when $T_{c}=T_{m}$.

\section{FINITE ELEMENT FORMULATION}

In the present study, the shell panels with constant thickness $h$ are considered. A Cartesian coordinate system $(x, y, z)$ with origin on the mid-plane is attached to the panel, assuming $(x, y)$ as the in-plane coordinates, and $z$ as the coordinate along the thickness. The surface of the shell panels is smooth and described by a function $z=f(x, y)$ as shown in Fig. 1. The projection of the panel on the $x y$-plane is a rectangle of length $a$ (in $x$-direction) and of width $b$ (in $y$-direction).

An eight-nodded middle surface shell element [27] is used. The global coordinates of arbitrary point in the above shell domain can be expressed using the nodal coordinates and isoparametric shape functions as

$$
\left\{\begin{array}{l}
x \\
y \\
z
\end{array}\right\}=\sum_{i=1}^{8} N_{i}(\xi, \eta)\left\{\left\{\begin{array}{l}
x_{i} \\
y_{i} \\
z_{i}
\end{array}\right\}+\zeta \frac{h}{2}\left\{\begin{array}{c}
l_{3 i} \\
m_{3 i} \\
n_{3 i}
\end{array}\right\}\right\},
$$

where $\left(l_{3 i}, m_{3 i}, n_{3 i}\right)$ are the direction cosines of the normal to mid-plane at node $i$, which is obtained by the cross product of two vectors, which are tangent to the reference surface at $i, N_{i}$ are the quadratic serendipity shape functions in $(\xi-\eta)$ plane.

The displacement field may be defined in terms of three displacement components $\left(u_{i}, v_{i}\right.$ and $\left.w_{i}\right)$ and two rotational components $\left(\theta_{x i}\right.$ and $\left.\theta_{y i}\right)$ at the mid-surface nodes as follows

$$
\left\{\begin{array}{c}
u \\
v \\
w
\end{array}\right\}=\sum_{i=1}^{8} N_{i}\left\{\begin{array}{c}
u_{i} \\
v_{i} \\
w_{i}
\end{array}\right\}+\sum_{i=1}^{8} N_{i} \zeta_{\frac{h}{2}}\left[\begin{array}{cc}
l_{1 i} & l_{2 i} \\
m_{1 i} & m_{2 i} \\
n_{1 i} & n_{2 i}
\end{array}\right]\left\{\begin{array}{c}
\theta_{x i} \\
\theta_{y i}
\end{array}\right\},
$$

where the displacement components $\left(u_{i}, v_{i}\right.$ and $\left.w_{i}\right)$ are taken along Cartesian coordinate system $(x, y$ and $z)$ and the rotational components $\left(\theta_{x i}\right.$ and $\left.\theta_{y i}\right)$ are taken about two mutually perpendicular lines tangential to the mid-surface having unit vectors as follows

$$
\left\{v_{1 i}\right\}=\left[\begin{array}{lll}
l_{1 i} & m_{1 i} & n_{1 i}
\end{array}\right]^{T} ; \quad\left\{v_{2 i}\right\}=\left[\begin{array}{lll}
l_{2 i} & m_{2 i} & n_{2 i}
\end{array}\right]^{T} .
$$


The strains are derivatives of the displacements and can be expressed as

$$
\{\varepsilon\}=\left\{\begin{array}{c}
\varepsilon_{x} \\
\varepsilon_{y} \\
\gamma_{x y} \\
\gamma_{y z} \\
\gamma_{x z}
\end{array}\right\}=\left\{\begin{array}{c}
u_{, x} \\
v, y \\
u_{, y}+v_{, x} \\
v_{, z}+w_{, y} \\
u_{, z}+w_{, x}
\end{array}\right\}=[B]\{q\}_{e}=\left[\left[B_{1}\right],\left[B_{2}\right], \ldots,\left[B_{8}\right]\right]\left\{\begin{array}{c}
\left\{q_{1}\right\} \\
\left\{q_{2}\right\} \\
\cdot \\
\cdot \\
\cdot \\
\left\{q_{8}\right\}
\end{array}\right\}
$$

where the matrix $[B]$ is called the strain-displacement matrix and $\left\{q_{i}\right\}=\left\{u_{i} v_{i} w_{i} \theta_{x i} \theta_{y i}\right\}^{T}$ is the nodal displacement vector. Here, $\left[B_{i}\right]$ is given by

$$
\left[B_{i}\right]=\left[\begin{array}{ccccc}
\frac{\partial N_{i}}{\partial \xi} & 0 & 0 & -\zeta \frac{h}{2} \frac{\partial N_{i}}{\partial \xi} l_{2 i} & \zeta \frac{h}{2} \frac{\partial N_{i}}{\partial \xi} l_{1 i} \\
0 & \frac{\partial N_{i}}{\partial \eta} & 0 & -\zeta \frac{h}{2} \frac{\partial N_{i}}{\partial \eta} m_{2 i} & \zeta \frac{h}{2} \frac{\partial N_{i}}{\partial \mu} m_{1 i} \\
\frac{\partial N_{i}}{\partial \eta} & \frac{\partial N_{i}}{\partial \xi} & 0 & -\zeta \frac{h}{2}\left(\frac{\partial N_{i}}{\partial \eta} l_{2 i}+\frac{\partial N_{i}}{\partial \xi} m_{2 i}\right) & \zeta \frac{h}{2}\left(\frac{\partial N_{i}}{\partial \eta} l_{1 i}+\frac{\partial N_{i}}{\partial \xi} m_{1 i}\right) \\
0 & 0 & \frac{\partial N_{i}}{\partial \xi} & -\frac{h}{2}\left(l_{2 i} N_{i}+\zeta \frac{\partial N_{i}}{\partial \xi} n_{2 i}\right) & \frac{h}{2}\left(l_{1 i} N_{i}+\zeta \frac{\partial N_{i}}{\partial \xi} n_{1 i}\right) \\
0 & 0 & \frac{\partial N_{i}}{\partial \eta} & -\frac{h}{2}\left(m_{2 i} N_{i}+\zeta \frac{\partial N_{i}}{\partial \eta} n_{2 i}\right) & \frac{h}{2}\left(m_{1 i} N_{i}+\zeta \frac{\partial N_{i}}{\partial \eta} n_{1 i}\right)
\end{array}\right]
$$

where $i=1 \div 8$ for an eight-nodded shell element.

The above displacement field is defined in the global coordinates $(x, y, z)$ but material properties are available in the local coordinates $\left(x^{\prime}, y^{\prime}, z^{\prime}\right)$. Therefore, the strains need to be transformed from global to local coordinate. The local strains $\left\{\varepsilon^{\prime}\right\}$ are related to the global strains $\{\varepsilon\}$ as

$$
\left\{\varepsilon^{\prime}\right\}=\left\{\begin{array}{c}
\varepsilon_{x^{\prime}} \\
\varepsilon_{y^{\prime}} \\
\gamma_{x^{\prime} y^{\prime}} \\
\gamma_{y^{\prime} z^{\prime}} \\
\gamma_{x^{\prime} z^{\prime}}
\end{array}\right\}=\left\{\begin{array}{c}
u_{, x^{\prime}} \\
v_{, y^{\prime}} \\
u_{, y^{\prime}}+v_{, x^{\prime}} \\
v_{z^{\prime}}+w_{, y^{\prime}} \\
u_{, z^{\prime}}+w_{, x^{\prime}}
\end{array}\right\}=\left[T_{\varepsilon}\right]\left\{\begin{array}{c}
\varepsilon_{x} \\
\varepsilon_{y} \\
\gamma_{x y} \\
\gamma_{y z} \\
\gamma_{x z}
\end{array}\right\}=\left[T_{\varepsilon}\right]\{\varepsilon\},
$$

where $\left[T_{\varepsilon}\right]$ is the strain transformation matrix given by

$$
\left[T_{\varepsilon}\right]=\left[\begin{array}{ccccc}
l_{1}^{2} & m_{1}^{2} & l_{1} m_{1} & m_{1} n_{1} & n_{1} l_{1} \\
l_{2}^{2} & m_{2}^{2} & l_{2} m_{2} & m_{2} n_{2} & n_{2} l_{2} \\
2 l_{1} l_{2} & 2 m_{1} m_{2} & l_{1} m_{2}+l_{2} m_{1} & m_{1} n_{2}+m_{2} n_{1} & n_{1} l_{2}+n_{2} l_{1} \\
2 l_{2} l_{3} & 2 m_{2} m_{3} & l_{2} m_{3}+l_{3} m_{2} & m_{2} n_{3}+m_{3} n_{2} & n_{2} l_{3}+n_{3} l_{2} \\
2 l_{3} l_{1} & 2 m_{3} m_{1} & l_{3} m_{1}+l_{1} m_{3} & m_{3} n_{1}+m_{1} n_{3} & n_{3} l_{1}+n_{1} l_{3}
\end{array}\right],
$$

where, $l_{1}, l_{2}, l_{3}, m_{1}, m_{2}, m_{3}, n_{1}, n_{2}, n_{3}$ are the corresponding direction cosines between the global coordinate system and local coordinate system.

The strains in the local coordinates can be written as

$$
\left\{\varepsilon^{\prime}\right\}=\left[B^{\prime}\right]\{q\}_{e}=\left[T_{\varepsilon}\right][B]\{q\}_{e},
$$


where, the strain-displacement matrix corresponding to the local coordinates $\left[B^{\prime}\right]$ is given by

$$
\left[B^{\prime}\right]=\left[T_{\varepsilon}\right][B] .
$$

The stress-strain relationship is given as follows

$$
\left.\left.\left\{\begin{array}{c}
\sigma_{x} \\
\sigma_{y} \\
\sigma_{x y} \\
\sigma_{y z} \\
\sigma_{x z}
\end{array}\right\}=\left[\begin{array}{ccccc}
\frac{E(z, T)}{\left[1-v^{2}(z, T)\right]} & \frac{v E(z, T)}{\left[1-v^{2}(z, T)\right]} & 0 & 0 & 0 \\
\frac{v E(z, T)}{\left[1-v^{2}(z, T)\right]} & \frac{E(z, T)}{\left[1-v^{2}(z, T)\right]} & 0 & 0 & 0 \\
0 & 0 & \frac{E(z, T)}{2[1-v(z, T)]} & 0 & 0 \\
0 & 0 & 0 & \frac{k_{s} E(z, T)}{2[1-v(z, T)]} & 0 \\
0 & 0 & 0 & 0 & \frac{k_{s} E(z, T)}{2[1-v(z, T)]}
\end{array}\right]\right\} \begin{array}{c}
\varepsilon_{x} \\
\varepsilon_{y} \\
\gamma_{x y} \\
\gamma_{y z} \\
\gamma_{x z}
\end{array}\right\},
$$

or

$$
\{\sigma\}=[D]\{\varepsilon\}
$$

where $k_{s}$ is the shear correction factor, and is taken as $5 / 6$.

By using Hamilton's principle with the help of Eqs. (15) and (17), it is easy to obtain the stiffness matrix of an element

$$
\left[K_{e}\right]=\int_{V}[B]^{T}\left[T_{\varepsilon}\right]^{T}\left[D^{\prime}\right]\left[T_{\varepsilon}\right][B] d V=\int_{-1}^{1} \int_{-1}^{1} \int_{-1}^{1}[B]^{T}\left[T_{\varepsilon}\right]^{T}\left[D^{\prime}\right]\left[T_{\varepsilon}\right][B]|J| d \xi d \eta d \zeta,
$$

where $|J|$ is the determinant of the Jacobian matrix $[J]$, which can be obtained with the help of Eq. (7), taking derivatives of $x, y$ and $z$ with respect to $\xi, \eta$ and $\zeta$.

Following the usual techniques, mass element matrix also can be obtained from Hamilton's principle with the help of Eq. (7) and can be written as follow

$$
\left[M_{e}\right]=\int_{V} \rho(z)\left[N_{D}\right]^{T}\left[N_{D}\right] d V=\int_{-1}^{1} \int_{-1}^{1} \int_{-1}^{1} \rho(z)\left[N_{D}\right]^{T}\left[N_{D}\right]|J| d \xi d \eta d \zeta,
$$

where $\rho(z)$ is the material density and

$$
\begin{gathered}
{\left[N_{D}\right]=\left[\begin{array}{lllll}
N_{D 1} & N_{D 2} & \ldots & N_{D 8}
\end{array}\right],} \\
{\left[N_{D i}\right]=\left[\begin{array}{ccccc}
N_{i} & 0 & 0 & \frac{\zeta h_{i}}{2} l_{1 i} N_{i} & \frac{\zeta h_{i}}{2} l_{2 i} N_{i} \\
0 & N_{i} & 0 & \frac{\zeta h_{i}}{2} m_{1 i} N_{i} & \frac{\zeta h_{i}}{2} m_{2 i} N_{i} \\
0 & 0 & N_{i} & \frac{\zeta h_{i}}{2} n_{1 i} N_{i} & \frac{\zeta h_{i}}{2} n_{2 i} N_{i}
\end{array}\right] .}
\end{gathered}
$$

The governing equation of motion for an element can be given by

$$
[M]_{e}\{\ddot{q}\}_{e}+[K]_{e}\{q\}_{e}=\{0\} .
$$


By assembling element matrices, the general free vibration equation of the structure is obtained as

$$
[M]\{\ddot{q}\}+[K]\{q\}=\{0\},
$$

where $[M]$ is global mass matrix, $[K]$ is global stiffness matrix, $\{q\}$ is global nodal displacement vector, $\{\ddot{q}\}$ is acceleration of motion.

The following four boundary conditions are considered herein

(1) Simply supported (SSSS): $u_{0}=w_{0}=\theta_{y}=0$ at $x=0$, $a$ and $v_{0}=w_{0}=\theta_{x}=0$ at $y=0, b$;

(2) Clamped (CCCC): $u_{0}=v_{0}=w_{0}=\theta_{x}=\theta_{y}=0$ at $x=0, a$ and $y=0, b$;

(3) Simply supported-clamped (SCSC): $u_{0}=w_{0}=\theta_{y}=0$ at $x=0, a$ and $u_{0}=v_{0}=$ $w_{0}=\theta_{x}=\theta_{y}=0$ at $y=0, b$;

(4) Clamped-free (CFCF): $u_{0}=v_{0}=w_{0}=\theta_{x}=\theta_{y}=0$ at $x=0, a$;

where $u_{0}, v_{0}$, and $w_{0}$ are corresponding displacements of a point on the mid-plane and $\theta_{x}$ and $\theta_{y}$ are the rotations of normal to the mid-plane about the $y$-axis and $x$-axis, respectively.

\section{RESULTS AND DISCUSSIONS}

Consider a shell panel made of ceramic $\left(\mathrm{Si}_{3} \mathrm{~N}_{4}\right)$ and metal (SUS304), the properties of which are assumed to be temperature-dependent and they are obtained by using Eq. (2). The temperature-dependent coefficients of the material properties of constituents are shown in Tab. 1 [1].

Table 1. Temperature-dependent coefficients for ceramic and metals

\begin{tabular}{ccccccc}
\hline Material & Properties & $P_{0}$ & $P_{-1}$ & $P_{1}$ & $P_{2}$ & $P_{3}$ \\
\hline & $E_{c}(\mathrm{~Pa})$ & $348.43 \times 10^{9}$ & 0 & $-3.07 \times 10^{4}$ & $2.16 \times 10^{7}$ & $-8.946 \times 10^{-11}$ \\
$\mathrm{Si}_{3} \mathrm{~N}_{4}$ & $\alpha_{c}(1 / \mathrm{K})$ & $5.8723 \times 10^{-6}$ & 0 & $9.095 \times 10^{-4}$ & 0 & 0 \\
$($ Ceramic $)$ & $K_{c}(\mathrm{~W} / \mathrm{mK})$ & 13.723 & 0 & $-1.032 \times 10^{-3}$ & $5.466 \times 10^{-7}$ & $-7.876 \times 10^{-11}$ \\
& $\nu_{c}$ & 0.24 & 0 & 0 & 0 & 0 \\
& $\rho_{c}\left(\mathrm{~kg} / \mathrm{m}^{3}\right)$ & 2370 & 0 & 0 & 0 & 0 \\
\hline \multirow{2}{*}{ SUS304 } & $E_{m}(\mathrm{~Pa})$ & $201.04 \times 10^{9}$ & 0 & $3.079 \times 10^{-4}$ & $-6.53 \times 10^{-7}$ & 0 \\
(Metal $)$ & $\alpha_{m}(1 / \mathrm{K})$ & $12.33 \times 10^{-6}$ & 0 & $8.086 \times 10^{-4}$ & 0 & 0 \\
& $K_{m}(\mathrm{~W} / \mathrm{mK})$ & 15.379 & 0 & $-1.264 \times 10^{-3}$ & $2.09 \times 10^{-6}$ & $-7.223 \times 10^{-10}$ \\
& $\nu_{m}$ & 0.3262 & 0 & $-2.002 \times 10^{-4}$ & $3.797 \times 10^{-7}$ & 0 \\
& $\rho_{m}\left(\mathrm{~kg} / \mathrm{m}^{3}\right)$ & 8166 & 0 & 0 & 0 & 0 \\
\hline
\end{tabular}

\subsection{Convergence and validation}

After checking convergence, a $12 \times 12$ mesh of eight-nodded element has been used in the computation. In order to validate the accuracy of the present model, non-dimensional fundamental natural frequencies of a singly curved FG panel (cylindrical shell panel) and doubly curved FG panel in thermal environments are calculated and presented in 
Tabs. 2 and 3, respectively. The obtained results are compared with results of Shen and Wang [17], and of Shen et al. [28] based on a higher order shear deformation shell theory and two-step perturbation approach.

Table 2. Comparison of non-dimensional natural frequencies for a simply-supported $\mathrm{Si}_{3} \mathrm{~N}_{4} / \mathrm{SUS304}$ cylindrical panel with different values of volume fraction index in thermal environment

\begin{tabular}{llccccc}
\hline \multirow{2}{*}{ Temperature } & \multirow{2}{*}{ Source } & \multicolumn{5}{c}{ The volume fraction index $(p)$} \\
\cline { 3 - 7 } & & $p=0$ & $p=0.5$ & $p=1$ & $p=2$ & $p=5$ \\
\hline \multirow{2}{*}{$T_{c}=400 \mathrm{~K}}$, & Shen and Wang [17] & 25.5998 & 17.4628 & 15.1410 & 13.3723 & 11.9620 \\
$T_{m}=400 \mathrm{~K}$ & Present (FEM) & 25.4781 & 17.7689 & 15.5157 & 13.7471 & 12.2930 \\
& Difference (\%) & 0.48 & 1.75 & 2.47 & 2.80 & 2.77 \\
\hline \multirow{2}{*}{$T_{c}=500 \mathrm{~K}}$, & Shen and Wang [17] & 25.3065 & 17.4568 & 15.2093 & 13.4861 & 12.0950 \\
$T_{m}=300 \mathrm{~K}$ & Present (FEM) & 25.4832 & 17.7608 & 15.5045 & 13.7347 & 12.2810 \\
& Difference (\%) & 0.70 & 1.74 & 1.94 & 1.84 & 1.54 \\
\hline
\end{tabular}

Table 3. Comparison of non-dimensional natural frequencies for simply-supported $\mathrm{Si}_{3} \mathrm{~N}_{4}$ /SUS304 doubly-curved panels with different values of volume fraction index in thermal environment

\begin{tabular}{llccccc}
\hline \multirow{2}{*}{ Temperature } & \multirow{2}{*}{ Source } & \multicolumn{5}{c}{ The volume fraction exponent $p$} \\
\cline { 3 - 7 } & & $p=0$ & $p=0.5$ & $p=1$ & $p=2$ & $p=5$ \\
\hline \multirow{2}{*}{$T_{c}=400 \mathrm{~K}}$, & Shen et al. [28] & 12.6934 & 8.6883 & 7.5899 & 6.7887 & 6.1483 \\
$T_{m}=400 \mathrm{~K}$ & Present (FEM) & 12.8029 & 8.929 & 7.7968 & 6.908 & 6.1773 \\
& Difference (\%) & 0.86 & 2.70 & 2.65 & 1.73 & 0.47 \\
\hline \multirow{2}{*}{$T_{c}=500 \mathrm{~K}}$, & Shen et al. [28] & 12.5478 & 8.6898 & 7.6262 & 6.8414 & 6.2032 \\
$T_{m}=300 \mathrm{~K}$ & Present (FEM) & 12.8055 & 8.925 & 7.7912 & 6.9018 & 6.1713 \\
& Difference (\%) & 2.01 & 2.64 & 2.12 & 0.88 & 0.52 \\
\hline
\end{tabular}

The geometrical parameters of cylindrical panel are $h=0.001(\mathrm{~m}) ; a / b=1 ; b / h=$ $20 ; b / R=1$, whereas the doubly curved panel has $h=0.001(\mathrm{~m}) ; a / b=1 ; b / h=$ $10 ; a / R_{x}=0.1 ; b / R_{y}=0.05(a, b$ are the lengths in $x$, and $y$ directions respectively). The natural frequencies are calculated for two sets of thermal environmental conditions. For uniform temperature rise, $T_{c}=T_{m}=400 \mathrm{~K}$, and for non-linear temperature gradient across the thickness, $T_{m}=300 \mathrm{~K}$ and $T_{c}=500 \mathrm{~K}$. The non-dimensional natural frequency is defined by $\Omega_{1}=\omega\left(b^{2} / h\right) \sqrt{\rho_{0} / E_{0}}$, where $\rho_{0}$ and $E_{0}$ are the reference values of $\rho_{m}$ and $E_{m}$ at $T_{0}=300 \mathrm{~K}$.

These two comparison studies show that the results from the present formulation are in good agreement with the existing results. The discrepancy between the results is small (the maximum difference is $2.8 \%$ for cylindrical panels with $p=2$ under uniform temperature rise). 


\subsection{Parameter studies}

In this section, the effects of thickness, curvature, material composition, and boundary conditions on the fundamental natural frequencies of six different types of FG shell panels (Fig. 2) namely, cylindrical panel (CYL), spherical panel (SPH), hyperbolic paraboloid panel (HPR), hypar panel (HYP), conoid panel (CON), and parabolic panel (PAR) are investigated. The geometry equations of cylindrical, spherical, hyperbolic paraboloid panels are obtained from the geometry equation of doubly curved shell panel in Tab. 4.

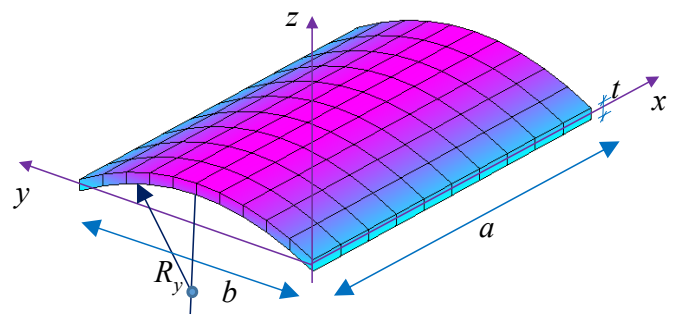

(a) Cylindrical (CYL)

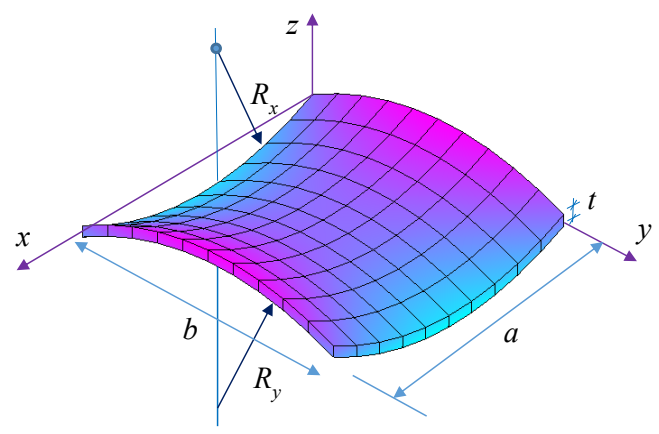

(c) Hyperbolic paraboloid shell (HPR)

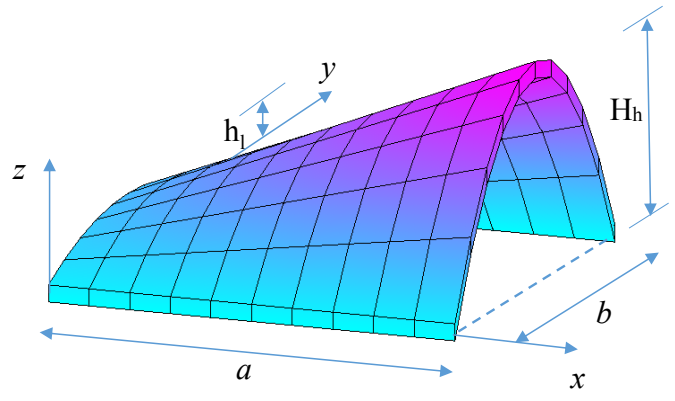

(e) Conoid (CON)

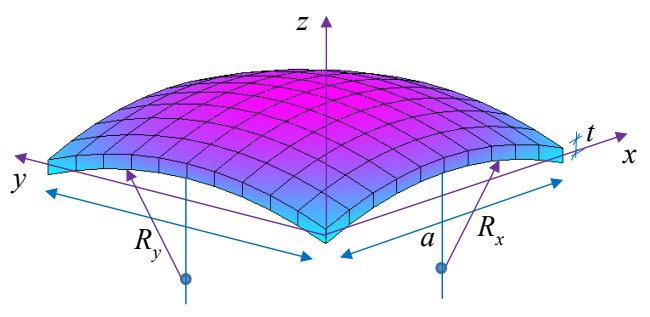

(b) Spherical (SPH)

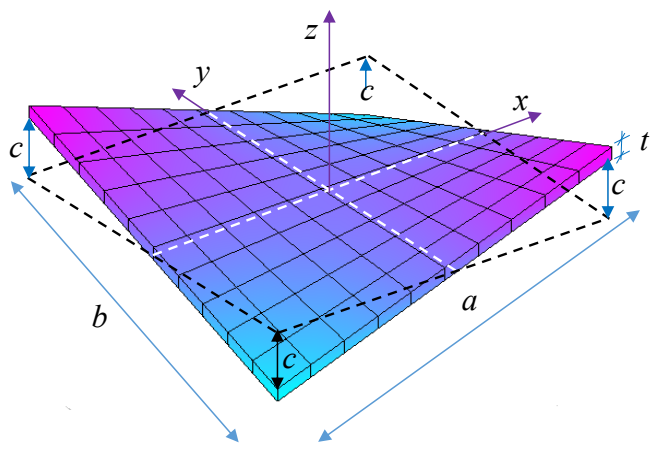

(d) Hypar (HYP)

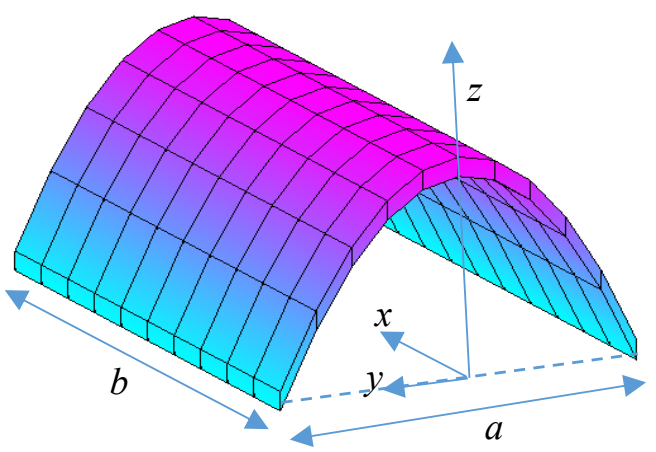

(f) Parabolic (PAR)

Fig. 2. Types of shell panels for investigation 
The non-dimensional natural frequency is defined as $\Omega_{2}=100 \omega h \sqrt{\rho_{0} / E_{0}}$, where $\rho_{0}$ and $E_{0}$ are the reference values of $\rho_{m}$ and $E_{m}$ at $T_{0}=300 \mathrm{~K}$.

Table 4. The geometry equations of various shell panels

\begin{tabular}{lcccccc}
\hline Structures & CYL & SPH & HPR & HYP & CON & PAR \\
\hline Equation & $z=\frac{1}{2 R_{x}}\left(x-\frac{a}{2}\right)^{2}+\frac{1}{2 R_{y}}\left(y-\frac{b}{2}\right)^{2}$ & $z=\frac{4 c}{a b} x y$ & $z=4\left[h_{l}+\left(H_{h}-h_{l}\right) \frac{x}{a}\right]\left[\frac{y^{2}}{b^{2}}-\frac{y}{b}\right]$ & $z=c x^{2}$ \\
\hline Curvatures & $R_{x}\left(R_{y}\right)=0$ & $R_{x}=R_{y}$ & $R_{x} R_{y}<0$ & - & - & - \\
\hline \multicolumn{7}{c}{$0 \leq x \leq a$ and $0 \leq y \leq b$} \\
\hline Figure & $2 a$ & $2 b$ & $2 c$ & $2 d$ & $2 e$ & $2 f$ \\
\hline
\end{tabular}

\subsubsection{Effect of thickness}

The effect of side-to-thickness ratio $(a / h)$ on the natural frequency of FG shell panels $(p=0.5)$ under influence of nonlinear gradient across the thickness with temperature conditions $T_{c}=600 \mathrm{~K}, T_{m}=300 \mathrm{~K}$ is considered. The non-dimensional fundamental natural frequencies of different types of shell panels are examined for side-to-thickness ratios varied from 10 to 100 . Results are plotted in Fig. 3 with two cases of boundary conditions, including all edges simply-supported (SSSS) and all edges clamped (CCCC). The geometrical parameters of different shell panels are:

- CYL: $a / R_{x}=0 ; b / R_{y}=1 / 3$; SPH: $a / R_{x}=b / R_{y}=1 / 3 ; \mathrm{HPR}: a / R_{x}=$ $2 ; b / R_{y}=-a / R_{x}$;

- HYP: $c / a=0.1 ; \mathrm{CON}: a / H_{h}=5 ; h_{l}=0.2 H_{h} ;$ PAR: $c / a=0.2$.

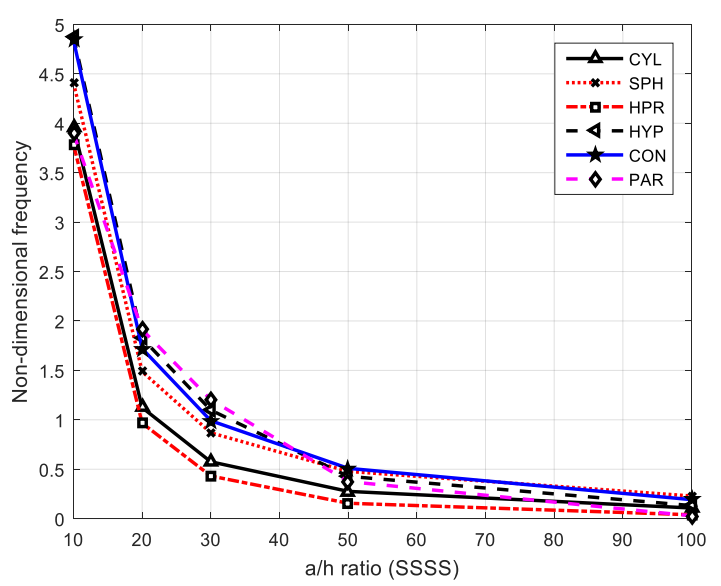

(a) SSSS

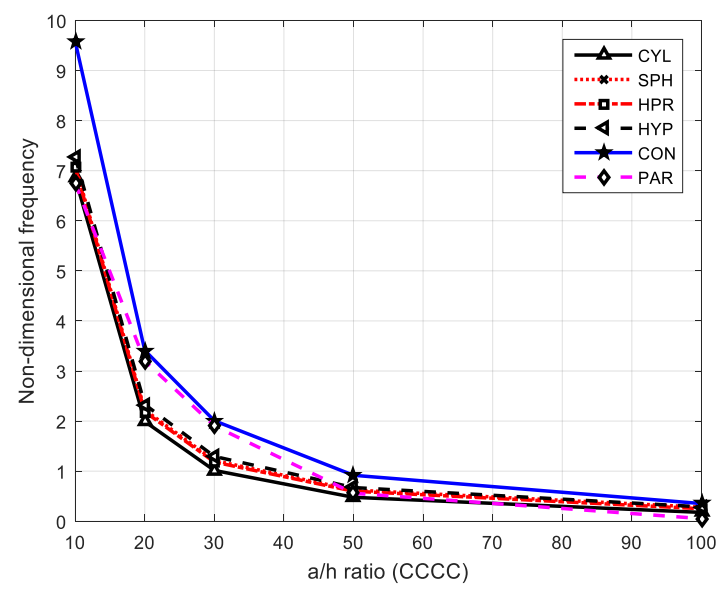

(b) $\mathrm{CCCC}$

Fig. 3. Effect of side-to-thickness ratio $(a / h)$ on $\Omega_{2}$ of FG shell panels 
From Fig. 3, it can be observed that the non-dimensional frequencies of all shell panels decrease rapidly with increasing $a / h$ ratios. For the SSSS boundary conditions, the parabolic shell panel has the highest natural frequency and hypar shell panel has the lowest natural frequency. For the CCCC boundary conditions, the conoid shell has the highest natural frequency and cylindrical shell panel has the lowest natural frequency.

\subsubsection{Effect of curvatures}

The simply supported FG shell panels (SSSS) with volume fraction index $p=5$, length-to-thickness ratio $a / h=10$, aspect ratio $a / b=1$ under influence of nonlinear temperature field with temperature boundary conditions of $T_{c}=600 \mathrm{~K}, T_{m}=300 \mathrm{~K}$ are considered. Tab. 5 lists the non-dimensional fundamental natural frequencies of six types of FG shell panels for various curvature parameters.

It can be seen that the non-dimensional natural frequencies increase as curvature parameters increase. It implies that shell panels become stiffer as the panels become more curved for CYL, SPH, CON, HYP and PAR panels, except for hyperbolic paraboloidal shell panel (HPR), the non-dimensional natural frequencies decrease with increasing curvature parameters.

Table 5. Effect of various curvature parameters on non-dimensional frequencies of FG shell panels

\begin{tabular}{|c|c|c|c|c|c|c|c|c|c|c|c|}
\hline \multirow{2}{*}{ CYL } & $b / R_{y}$ & 0 & $1 / 10$ & $1 / 5$ & $1 / 3$ & \multirow{2}{*}{$\mathrm{CON}$} & $h_{1} / H_{h}$ & 0 & 0.05 & 0.10 & 0.15 \\
\hline & & 0.6710 & 0.6812 & 0.7108 & 0.7761 & & & 1.3470 & 1.3796 & 1.3969 & 1.3998 \\
\hline \multirow{2}{*}{$\mathrm{SPH}$} & $b / R_{y}$ & 0 & $1 / 10$ & $1 / 5$ & $1 / 3$ & \multirow{2}{*}{ HYP } & $c / a$ & 0 & 0.05 & 0.10 & 0.15 \\
\hline & & 0.6710 & 0.7112 & 0.8192 & 1.0270 & & & 0.6710 & 0.8633 & 1.2602 & 1.6177 \\
\hline \multirow{2}{*}{ HPR } & $b / R_{y}$ & 0 & $1 / 10$ & $1 / 5$ & $1 / 3$ & \multirow{2}{*}{ PAR } & $c / a$ & 0 & 1.00 & 2.00 & 3.00 \\
\hline & & 0.6710 & 0.6706 & 0.6695 & 0.6673 & & & 0.6710 & 0.8885 & 1.3201 & 1.6191 \\
\hline
\end{tabular}

\subsubsection{Effect of boundary conditions and material composition}

In order to understand the effect of material composition and boundary conditions on the free vibration characteristic of FG shell panels, the non-dimensional fundamental frequencies of six types of shell panels with various boundary conditions and different values of volume fraction index are determined. Four types of boundary condition, including all edges simply-supported (SSSS), two sides clamped and two sides free (CFCF), two sides simply-supported and two sides clamped (SCSC) and all edges clamped (CCCC) are considered. The geometric parameters of FG shells are $h=0.025 \mathrm{~m}$; $a / h=20 ; a / b=1$; nonlinear temperature field with thermal environmental conditions $T_{c}=500 \mathrm{~K}, T_{m}=300 \mathrm{~K}$.

Non-dimensional frequencies of six types of FG panels with four boundary conditions, and different values of volume fraction index are presented in Tab. 6. As can be seen from the presented results, the non-dimensional natural frequency of all types of FG panels decreases with increasing value of volume fraction index $p$. It is because Young's modulus of ceramic is higher than of metal. 
It is also found that the shell panels with CCCC boundary condition have higher natural frequency than others. This means that an increase in the number of edge restraints increases the stiffness of the shell panels.

Table 6. Effect of various boundary conditions and volume fraction index $(p)$ on non-dimensional frequencies $\Omega_{2}$ of FG shell panels

\begin{tabular}{cccccc}
\hline \multirow{2}{*}{ Structures } & & \multicolumn{4}{c}{ Boundary conditions } \\
\cline { 3 - 6 } & & SSSS & CFCF & SCSC & CCCC \\
\hline \multirow{2}{*}{$\left(a / R_{x}=0 ; b / R_{y}=1 / 3\right)$} & 0 & 1.6203 & 1.7146 & 2.1697 & 2.8713 \\
& 1 & 0.9858 & 1.0432 & 1.3201 & 1.7470 \\
SPH & 5 & 0.7809 & 0.8263 & 1.0456 & 1.3838 \\
\hline $\left.1 / 3 ; R_{y}=R_{x}\right)$ & 0 & 2.1441 & 2.1595 & 2.6112 & 3.2039 \\
$\left(a / R_{x}=\right.$ & 1 & 1.3045 & 1.3139 & 1.5887 & 1.9492 \\
HPR & 5 & 1.0333 & 1.0407 & 1.2583 & 1.5439 \\
\hline \multirow{2}{*}{$\left(a / R_{x}=1 / 3 ; R_{y}=-R_{x}\right)$} & 0 & 1.3931 & 2.1697 & 2.4918 & 3.1522 \\
$(c / a=0.1)$ & 1 & 0.8476 & 1.3202 & 1.5161 & 1.9180 \\
& 5 & 0.6714 & 1.0457 & 1.2009 & 1.5193 \\
\hline \multirow{2}{*}{$\mathrm{CON}$} & 0 & 2.6300 & 2.2705 & 2.8133 & 3.3606 \\
$\left(a / H_{h}=1 ; h_{l}=0.5 H_{h}\right)$ & 1 & 1.6004 & 1.3816 & 1.7118 & 2.0448 \\
& 5 & 1.2679 & 1.0944 & 1.3560 & 1.6198 \\
\hline \multirow{2}{*}{$\mathrm{PAR}$} & 0 & 2.5168 & 2.0095 & 3.1109 & 3.6084 \\
$(c / a=10)$ & 5 & 1.5313 & 1.2227 & 1.8928 & 2.1956 \\
& 0 & 2.8305 & 2.0303 & 3.3985 & 3.9564 \\
& 1 & 1.7221 & 1.2354 & 2.0678 & 2.4073 \\
& 5 & 1.3641 & 0.9786 & 1.6380 & 1.9069 \\
\hline
\end{tabular}

Therefore, the material composition and boundary conditions play an important role in the vibration behavior of FG shell panels.

\subsubsection{Effect of temperature $\left(T_{c}\right)$}

The effects of non-linear gradient across the thickness $\left(\Delta T=T_{c}-T_{m}\right)$ on fundamental natural frequencies of FG shell panels are investigated in this section. The natural frequencies of various types of shell panels are calculated for nonlinear temperature distribution under temperature condition with $T_{m}=100 \mathrm{~K}$ on the metal-rich surface (bottom surface) and different values of temperature $T_{c}$ on the ceramic-rich surface (top surface). Obtained results with SSSS and CCCC boundary conditions are presented in Tab. 7. As can be seen from the presented results, the non-dimensional natural frequency decreases as temperature difference between the bottom surface and the top surface increases. There is a slight effect of non-linear temperature rise on the non-dimensional natural frequency in this case. 
Table 7. Effect of temperature on non-dimensional frequencies $\Omega_{2}$ of FG shell panels with simplysupported and clamped boundary conditions

\begin{tabular}{ccccccc}
\hline \multirow{2}{*}{ Structures } & \multirow{5}{c}{$T_{\mathcal{c}}(\mathrm{K})$} \\
\cline { 3 - 7 } & & 200 & 300 & 400 & 500 & 700 \\
\hline CYL & SSSS & 4.2612 & 4.2392 & 4.2184 & 4.1984 & 4.1597 \\
$\left(a / R_{x}=0 ; b / R_{y}=1 / 2\right)$ & CCCC & 7.3327 & 7.2949 & 7.2591 & 7.2247 & 7.1582 \\
\hline SPH & SSSS & 5.1677 & 5.1411 & 5.1158 & 5.0916 & 5.0447 \\
$\left(a / R_{x}=1 / 2 ; R_{y}=R_{x}\right)$ & CCCC & 7.8695 & 7.8289 & 7.7904 & 7.7535 & 7.6821 \\
\hline HPR & SSSS & 3.8643 & 3.8444 & 3.8255 & 3.8073 & 3.7723 \\
$\left(a / R_{x}=1 / 2 ; R_{y}=-R_{x}\right)$ & CCCC & 7.7730 & 7.7330 & 7.6950 & 7.6586 & 7.5882 \\
\hline HYP & SSSS & 5.0093 & 4.9835 & 4.9591 & 4.9356 & 4.8902 \\
$(c / a=0.1)$ & CCCC & 7.4701 & 7.4317 & 7.3952 & 7.3601 & 7.2925 \\
\hline CON & SSSS & 5.2110 & 5.1841 & 5.1587 & 5.1342 & 5.0870 \\
$\left(a / H_{h}=1 ; h_{l}=0.5 H_{h}\right)$ & CCCC & 7.0027 & 6.9667 & 6.9325 & 6.8996 & 6.8362 \\
\hline PAR & SSSS & 5.6388 & 5.6098 & 5.5822 & 5.5557 & 5.5046 \\
$(c / a=10)$ & CCCC & 9.3292 & 9.2811 & 9.2355 & 9.1917 & 9.1072 \\
\hline
\end{tabular}

\section{CONCLUSIONS}

An eight-nodded middle surface shell element based on first order shear deformation theory has been developed for vibration analysis of FG shell panels in thermal environment. The shell's surfaces of various geometric shapes can be described by a function of Cartesian coordinates. The material properties are assumed to be temperaturedependent and graded in the thickness direction according to a power law function. Convergence and validation studies have been carried out to verify the accuracy of the present formulation. The influence of various parameters, such as the volume fraction exponent, side-to-thickness ratio, boundary conditions, curvature and temperature rise on the free vibration behavior of six different shell panels namely, cylindrical panel (CYL), spherical panel (SPH), hyperbolic paraboloid panel (HPR), hypar panel (HYP), conoid panel (CON) and parabolic panel (PAR) were investigated. The following points can be outlined from the present study:

The middle surface shell element is appropriately used to simulate the FG shell panels with various geometric shapes. This element involves less computation compared to the solid-type shell element.

An increase in the curvature parameters $b / R_{y}$ for CYL, SPH and HPR, $c / a$ for HYP and PAR, and $h_{l} / H_{h}$ for CON leads to an increase in shell panel stiffness for all six shell panels, and also increase of non-dimensional fundamental natural frequencies.

The decrease of non-dimensional frequency of all six FG shell panels with increasing volume fraction index $p$ can be attributed to the fact that Young's modulus of ceramic is higher than metal. 
Shell panels with CCCC boundary condition give the highest values of the nondimensional frequencies for all six FG shell panels considered. The shell panels become stiffer with higher number of edge restrains.

The non-dimensional fundamental frequencies of the shell panels also decrease slightly with a temperature rise.

\section{REFERENCES}

[1] J. N. Reddy and C. D. Chin. Thermomechanical analysis of functionally graded cylinders and plates. Journal of Thermal Stresses, 21, (6), (1998), pp. 593-626. https://doi.org/10.1080/01495739808956165.

[2] X. Zhao, Y. Y. Lee, and K. M. Liew. Thermoelastic and vibration analysis of functionally graded cylindrical shells. International Journal of Mechanical Sciences, 51, (9-10), (2009), pp. 694-707. https://doi.org/10.1016/j.ijmecsci.2009.08.001.

[3] C. T. Loy, K. Y. Lam, and J. N. Reddy. Vibration of functionally graded cylindrical shells. International Journal of Mechanical Sciences, 41, (3), (1999), pp. 309-324. https://doi.org/10.1016/s0020-7403(98)00054-x.

[4] A. G. Shah, T. Mahmood, M. N. Naeem, Z. Iqbal, and S. H. Arshad. Vibrations of functionally graded cylindrical shells based on elastic foundations. Acta Mechanica, 211, (3-4), (2010), pp. 293-307. https://doi.org/10.1007/s00707-009-0225-9.

[5] M. Jabbari, S. Sohrabpour, and M. R. Eslami. Mechanical and thermal stresses in a functionally graded hollow cylinder due to radially symmetric loads. International Journal of Pressure Vessels and Piping, 79, (7), (2002), pp. 493-497. https://doi.org/10.1016/s0308-0161(02)000431.

[6] S. S. Vel. Exact elasticity solution for the vibration of functionally graded anisotropic cylindrical shells. Composite Structures, 92, (11), (2010), pp. 2712-2727. https://doi.org/10.1016/j.compstruct.2010.03.012.

[7] H. Awaji and R. Sivakumar. Temperature and stress distributions in a hollow cylinder of functionally graded material: the case of temperature-independent material properties. Journal of the American Ceramic Society, 84, (5), (2001), pp. 1059-1065. https://doi.org/10.1111/j.1151-2916.2001.tb00790.x.

[8] M. M. Najafizadeh and M. R. Isvandzibaei. Vibration of functionally graded cylindrical shells based on different shear deformation shell theories with ring support under various boundary conditions. Journal of Mechanical Science and Technology, 23, (8), (2009), pp. 2072-2084. https://doi.org/10.1007/s12206-009-0432-2.

[9] F. Tornabene, E. Viola, and D. J. Inman. 2-D differential quadrature solution for vibration analysis of functionally graded conical, cylindrical shell and annular plate structures. Journal of Sound and Vibration, 328, (3), (2009), pp. 259-290. https://doi.org/10.1016/j.jsv.2009.07.031.

[10] S. Takezono, K. Tao, E. Inamura, and M. Inoue. Thermal stress and deformation in functionally graded material shells of revolution under thermal loading due to fluid. JSME International Journal. Ser. A, Mechanics and Material Engineering, 39, (4), (1996), pp. 573-581. https://doi.org/10.1299/kikaia.62.474.

[11] H. Matsunaga. Free vibration and stability of functionally graded shallow shells according to a 2D higher-order deformation theory. Composite Structures, 84, (2), (2008), pp. 132-146. https://doi.org/10.1016/j.compstruct.2007.07.006.

[12] G. R. Ye, W. Q. Chen, and J. B. Cai. A uniformly heated functionally graded cylindrical shell with transverse isotropy. Mechanics Research Communications, 5, (28), (2001), pp. 535542. https://doi.org/10.1016/s0093-6413(01)00206-3. 
[13] K. M. Liew, S. Kitipornchai, X. Z. Zhang, and C. W. Lim. Analysis of the thermal stress behaviour of functionally graded hollow circular cylinders. International Journal of Solids and Structures, 40, (10), (2003), pp. 2355-2380. https://doi.org/10.1016/s0020-7683(03)00061-1.

[14] S. Pradyumna and J. N. Bandyopadhyay. Free vibration and buckling of functionally graded shell panels in thermal environments. International Journal of Structural Stability and Dynamics, 10, (05), (2010), pp. 1031-1053. https://doi.org/10.1142/s0219455410003889.

[15] F. Alijani, M. Amabili, and F. Bakhtiari-Nejad. Thermal effects on nonlinear vibrations of functionally graded doubly curved shells using higher order shear deformation theory. Composite Structures, 93, (10), (2011), pp. 2541-2553. https://doi.org/10.1016/j.compstruct.2011.04.016.

[16] H. S. Shen and Z. X. Wang. Assessment of Voigt and Mori-Tanaka models for vibration analysis of functionally graded plates. Composite Structures, 94, (7), (2012), pp. 2197-2208. https://doi.org/10.1016/j.compstruct.2012.02.018.

[17] H. S. Shen and H. Wang. Nonlinear vibration of shear deformable FGM cylindrical panels resting on elastic foundations in thermal environments. Composites Part B: Engineering, 60, (2014), pp. 167-177. https://doi.org/10.1016/j.compositesb.2013.12.051.

[18] N. Wattanasakulpong and A. Chaikittiratana. An analytical investigation on free vibration of FGM doubly curved shallow shells with stiffeners under thermal environment. Aerospace Science and Technology, 40, (2015), pp. 181-190. https://doi.org/10.1016/j.ast.2014.11.006.

[19] T. Q. Quan and N. D. Duc. Nonlinear vibration and dynamic response of shear deformable imperfect functionally graded double-curved shallow shells resting on elastic foundations in thermal environments. Journal of Thermal Stresses, 39, (4), (2016), pp. 437-459. https://doi.org/10.1080/01495739.2016.1158601.

[20] D. H. Bich, N. D. Duc, and T. Q. Quan. Nonlinear vibration of imperfect eccentrically stiffened functionally graded double curved shallow shells resting on elastic foundation using the first order shear deformation theory. International Journal of Mechanical Sciences, 80, (2014), pp. 16-28. https://doi.org/10.1016/j.ijmecsci.2013.12.009.

[21] D. H. Bich and H. V. Tung. Non-linear axisymmetric response of functionally graded shallow spherical shells under uniform external pressure including temperature effects. International Journal of Non-Linear Mechanics, 46, (9), (2011), pp. 1195-1204. https://doi.org/10.1016/j.ijnonlinmec.2011.05.015.

[22] D. H. Bich and V. Do Long. Non-linear vibration of eccentrically stiffened laminated composite shells. Vietnam Journal of Mechanics, 30, (2), (2008), pp. 67-70. https://doi.org/10.15625/0866-7136/30/2/5619.

[23] V. T. T. Anh, D. H. Bich, and N. D. Duc. Nonlinear stability of thin FGM annular spherical segment in thermal environment. Vietnam Journal of Mechanics, 37, (4), (2015), pp. 285-302. https://doi.org/10.15625/0866-7136/37/4/5962.

[24] D. T. Dong and D. Van Dung. Nonlinear vibration of functionally graded material sandwich doubly curved shallow shells reinforced by FGM stiffeners. Part 1: Governing equations. Vietnam Journal of Mechanics, 39, (3), (2017), pp. 245-257. https://doi.org/10.15625/0866$7136 / 9692$.

[25] J. Yang and H. S. Shen. Dynamic response of initially stressed functionally graded rectangular thin plates. Composite Structures, 54, (4), (2001), pp. 497-508. https://doi.org/10.1016/s0263-8223(01)00122-2.

[26] R. Javaheri and M. R. Eslami. Thermal buckling of functionally graded plates. AIAA Journal, 40, (1), (2002), pp. 162-169. https://doi.org/10.2514/3.15009. 
[27] S. Ahmad, B. M. Irons, and O. C. Zienkiewicz. Analysis of thick and thin shell structures by curved finite elements. International Journal for Numerical Methods in Engineering, 2, (3), (1970), pp. 419-451. https://doi.org/10.1002/nme.1620020310.

[28] H.-S. Shen, X. Chen, L. Guo, L. Wu, and X.-L. Huang. Nonlinear vibration of FGM doubly curved panels resting on elastic foundations in thermal environments. Aerospace Science and Technology, 47, (2015), pp. 434-446. https://doi.org/10.1016/j.ast.2015.10.011. 